\title{
Tecendo um mundo de diferenças
}

\section{Reinheimer, Patricia}

Resumo:

Essa comunicação pretende apresentar, a partir da trajetória e trabalho de uma tecelã teutobrasileira, a participação dos objetos, coleções e museus na urdidura de uma realidade fenomenológica onde a alteridade foi tecida em roupas como tema, cor e textura. Os museus, principalmente os etnológicos, foram o caminho que levou Olly a seus temas, assim como os museus de arte moderna foram uma das formas privilegiadas para o reconhecimento de sua produção como arte. Seu contato com antropólogos, colecionadores e museólogos contribuiu para que assumisse esses temas em sua produção, contribuindo Cuadernos del Centro de Estudios de Diseño y Comunicación N76

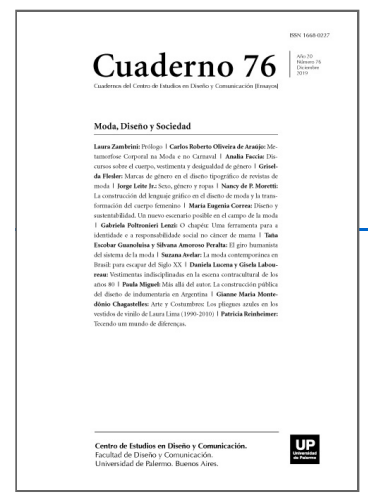

ISSN: 1668-0227

Moda, Diseño y

Sociedad

Año XX, Diciembre 2019, Buenos Aires, Argentina | 242 páginas

descargar PDF ver índice de la publicación

Ver todos los libros de la publicación

compartir en Facebook

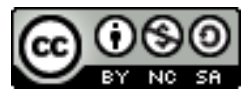
Esta obra está bajo una Licencia Creative Commons Atribución-NoComercialCompartirlgual 4.0 Internacional para a construção de uma modernidade imaginada para o país.

Palavras chave: moda - arte moderna - alteridade - design - nacionalidade - museus - coleções.

(*) Professora de Antropologia Social, da UFRRJ, tem se dedicado a investigar as transformações no estatuto de determinados objetos, buscando entender o papel das coisas na conformação de subjetividades e coletividades através de estilos de vida, produção e consumo cultural.

Introdução

Esse artigo pretende apresentar, a partir da trajetória e trabalho de uma tecelã teuto-brasileira, a participação dos objetos, coleções e museus na urdidura de uma realidade fenomenológica onde a alteridade foi tecida em roupas como tema, cor e textura.

Olly nasceu em 1914, em Mittweida, norte da Alemanha. Até o final do século XX, sua cidade natal foi relativamente importante devido à produção têxtil com teares mecânicos. Em 1936, mudou-se para o Brasil e, em 1950, começou uma carreira artística a partir de sua participação nas oficinas do Museu de Arte Moderna do 
Rio de Janeiro, pintando tecidos, com os quais criava roupas. O reconhecimento de seu trabalho pode ser remontado ao início da década de 1960, tendo atingido seu auge, na década de 1970, quando a tecelagem tornou-se sua principal técnica produtiva. A artista faleceu em 1986, no Rio de Janeiro, e a partir de então trilhou o caminho de uma crescente obscuridade.

Os museus, principalmente os etnológicos, foram o caminho que levou esta artista a seus temas, assim como os museus de arte moderna foram uma das formas privilegiadas para o reconhecimento de sua produção como arte. Ainda que o processo de musealização tenha sido global, com o uso dos mesmos conceitos na inauguração de instituições museais ao redor do mundo, a temporalidade de cada país e o sentido que esses conceitos foram adquirindo em cada contexto foi diferente (Chagas, 2007). No Brasil, a construção de museus com discursos específicos e dedicados a preocupações próprias à etnologia e à antropologia constituiu um fenômeno da segunda metade do século XX. Enquanto na Europa, ainda no século XIX, os museus etnográficos eram organizados em torno da produção de discursos de povos de "além-mar", ou seja, um "outro" geográfica e culturalmente distante, no Brasil, o "outro" era interno.

Com o final da Segunda Guerra e a fundação da UNESCO, a ideia de arte como uma linguagem comum através da qual as pessoas deveriam se entender e reforçar seus elos foi colocada em prática (Mascelani, 1999, pp. 131-132). Essa instituição, e suas parceiras em diferentes esferas culturais e regiões geográficas, deram ensejo à valorização de manifestações e produções culturais de grupos sociais diversos nos países associados. No entanto, somente em 20062 se pode identificar a institucionalização como parte do processo complexo de artificação (Heinich e Shapiro, 2012) dos, até então, artefatos de grupos pré-industrializados.

Esse caminho foi pavimentado ao longo de todo o século XX por exposições, principalmente na Europa3, que contribuíram, por um lado, para a crítica ao colonialismo no mundo artístico e, por outro, à reivindicação de individualização dos produtores e produtos desses grupos. Esse processo foi acompanhado por reflexões sobre diversas dimensões do fenômeno artístico: outras formas possíveis de autoria (Goldstein, 2012), a estética como categoria transcultural (Weiner, 1996), a lacuna entre o conceito de estética e as formas práticas de percepção (Campbell, 2010) e uma série de questões teóricas que constituem o campo de investigação da antropologia da arte, hoje.

Em relação à produção artística, alguns autores apontam, a partir da década de 1990, uma "virada etnográfica" no sistema internacional das artes. Belting, por exemplo, argumenta que a visão eurocêntrica que resultou na ideia de universalidade4, reivindicada pela modernidade artística, perdeu seu lugar. A ideia de arte autônoma que buscava um sentido na autonomia da história da arte, em grande medida coincidente com a era dos museus, deu lugar ao campo da cultura e da sociedade como contexto da arte contemporânea. A ideia de autonomia foi substituída por uma exigência de que a arte assumisse o lugar de testemunha nas mediações sociais e reivindicações políticas.

O trabalho de Terry Smith (2012) parece quase como uma confirmação dos argumentos de Belting. O autor abre sua introdução afirmando que qualquer tentativa de articular uma generalização acerca da arte contemporânea resultaria elusiva tanto pelo temor de cair no essencialismo das teorias exclusivistas, dos historicismos e dos grandes relatos, como pela simplificação de um campo aberto. Na busca de compreender a forma como a contemporaneidade permeou a prática da arte, Smith mostra como a partir dos anos 1950 a crescente percepção da multiplicidade gerada pela descolonização e o surgimento de uma economia globalizada de 
imagens deram ensejo na arte a "múltiplos modos de ser com, em e fora do tempo, separado e ao mesmo tempo, com outros e sem eles" (Smith, 2012, p. 21), que se tornam inequívocos a partir dos anos 1980. Entre as diversas correntes da arte contemporânea, então, se pode encontrar um expressivo grupo de artistas, historiadores, colecionadores e museólogos que produziram imersos em uma interatividade mediada e na tensão do intercâmbio entre afeto e efeito (Smith, 2012).

\section{A alteridade interna como estética nacional brasileira}

No entanto, até o início do século XXI, a estetização da produção de grupos não-industrializados era usada também como uma das estratégias para inverter o sinal negativo colocado sobre o que havia sido até então tratado como "vestígios de estágios inferiores" (Abreu, 2007). Foi em parte com esse pressuposto que, em 1947, inaugurou-se no Rio de Janeiro a primeira exposição de "arte popular" pernambucana, que tornaria famosa a cerâmica de Mestre Vitalino (Ver Figura 3). Seis anos depois, inaugurava-se o Museu de Arte Popular de Pernambuco.

Foi importante a participação de Gilberto Freire na construção desse museu. Eleito deputado federal pela União Democrática Nacional (UDN), entre 1946-1950, aproveitou o centenário de nascimento de Joaquim Nabuco para propor a criação do Instituto Joaquim Nabuco de Pesquisas Sociais. Na defesa do projeto, falou sobre o papel dos museus e sua importância no âmbito da pesquisa, do desenvolvimento social e da defesa dos valores regionais. Justificou assim a inclusão de um museu de Antropologia, "um museu de etnografia matuta e sertaneja, de arte popular, de indústria caseira” (Freire apud Abreu, 2007, p. 157). Na década de 1930, Gilberto Freire havia publicado uma trilogia que pretendia dar conta da história da sociedade patriarcal no Brasil. Nessa trilogia, assim como em toda sua obra e em sua vida pública, defendia um projeto de nação lusitana, ibérica e latina cuja especificidade seria a mistura de brancos, negros e índios.

Ainda que a miscigenação como fundamento da brasilidade não tenha sido criada por ele, sua inovação foi tornar isso um marco positivo da nacionalidade brasileira, afirmando uma sociedade democrática e exemplificando com as poucas exceções que se destacavam nas artes. Freire teve o título de doutor Honoris Causa em várias universidades europeias e sua obra foi traduzida em diversas línguas, particularmente "Casa Grande e Senzala". Sua produção tornou-se assim amplamente conhecida nacional e internacionalmente, difundindo a ideia de miscigenação como uma ideologia de formação nacional brasileira. Essa ideologia substituía a visão pessimista da contribuição das raças formadoras da sociedade brasileira por um enfoque positivo, no qual o intercurso racial transformou-se em indicador de tolerância e harmonia, tornando-se um dos principais alicerces ideológicos da integração racial e do desenvolvimento do país (Maio, 1998).

No Rio de Janeiro, em 1953, mesmo ano da fundação do Museu de Arte Popular de Pernambuco, Darcy Ribeiro abriu ao público o Museu do Índio, segundo ele, um museu contra o preconceito (Chagas, 2007). Desde a década de 1930, o Estado brasileiro já procurava controlar a saída de artefatos "musealizáveis" (Grupioni, 1998). A partir do final da década de 1940, a valorização do museu como instrumento político para reformulação de uma identidade nacional fundada na composição de diversos grupos minoritários tinha suscitado no Brasil um novo ímpeto colecionista, tanto estatal como privado.

As coleções regionais, por exemplo, foram formadas a partir de uma busca, no interior do país, por móveis antigos, estatuária barroca e objetos de arte popular. As pesquisas etnológicas, que se intensificaram após a 
fundação da Universidade de São Paulo e da Escola Livre de Sociologia e Política (USP e ELSP), por sua vez, foram responsáveis pela formação de coleções de objetos indígenas. Essas coleções foram organizadas na seção regional do Museu Nacional, assim como em museus de folclore e indígenas.

A coleta desses objetos foi parte de um amplo processo de identificação nacional que colocava em prática diversos sistemas de valoração e significação historicamente determinados. O que poderia ser denominado uma estatização da vida social era encenada por meio de exposições. Assim, diversos regimes de concepção e enunciação davam ensejo ao sertanejo, ao regional, ao folclórico, ao popular, ao indígena (Dias \& Lima, 2012).

Esses discursos e coleções, a partir da década de 1950, seriam o contraponto para a construção de uma hermenêutica de modernidade no Brasil. Muitos futuros marchands de arte estiveram envolvidos naquelas coletas (Bueno, 2005) e, em estreita relação com artistas e designers que aqui chegaram no período entre e pós-guerra, buscavam no pré-industrial uma origem autêntica para a modernidade brasileira, amparados também pelos recém- -fundados museus de arte moderna. Olly, por exemplo, que fez sua formação no Museu de Arte Moderna do Rio de Janeiro, na década de 1950, adquiriu diversos objetos de grupos indígenas e outros de artistas/artesãos classificados como populares e/ou regionais. Seu contato com antropólogos, colecionadores e museólogos contribuiu para que assumisse esses temas em sua produção, contribuindo para a construção dessa modernidade que se imaginava para o país5 .

Concomitante a esse processo de busca por uma identidade na alteridade interna, desde a década de 1950 é possível identificar no Brasil também um interesse pela cultura material dos povos pré-colombianos. O país era então inserido em um continente cuja grandiosidade do passado e projeção do futuro eram apresentadas através dos objetos de grupos variados, cuja unidade era dada pela colonização europeia. A modernidade latino-americana era forjada por associação e contraponto com os povos pré-colombianos, por oposição aos africanos que haviam contribuído para a formação de uma modernidade artística dos países centrais.

Nesse contexto, os objetos funcionavam dentro de sistemas de produção e reprodução de valores e subjetividades por meio de identidades e diferenciações operadas em diversos rituais e mitos urbanos. Em 1969, por exemplo, Olly apresentou uma exposição no Museu de Arte Moderna. Tratou-se de um evento que se assemelhava a um ritual no qual artistas e designers atuavam na ligação de um conjunto de símbolos cuja intenção, por um lado, era uma tentativa de eliminar tensões sociais, por outro, uma crítica política e afirmação de valores.

O tema principal da exposição eram as roupas produzidas a partir das pinturas corporais e das bonecas de barro dos índios karajá. A mostra contou com fotos de David Drew Zing6 e coordenação geral de Karl Heinz Bergmiller7 . Modelos desfilavam entre os convidados ao som de música, enquanto fotos eram projetadas nas paredes. A exposição foi patrocinada pelo Itamarati e, depois do Rio de Janeiro, seguiria para Copenhagen, Suécia, Finlândia, todo o norte da Europa e voltaria passando pela Alemanha8 (Jornal do Brasil, 1969).

Uma das contradições que a exposição colocava em foco era constitutiva do regime ditatorial que se inaugurou no Brasil a partir de 1964. Por um lado, estava a ideologia da miscigenação, proposta por Gilberto Freire, e abraçada por Darcy Ribeiro nas suas interpretações do Brasil. Por outro, as denúncias sobre o genocídio de índios que repercutiram na imprensa nacional e estrangeira, principalmente a partir de 1967, mostravam a hostilidade na relação entre os indígenas e o Estado9 . 
O colecionismo como engajamento ativo: uma modernidade possível

Diversas pesquisas já demonstraram a importância das coisas no processo de produção e reprodução social, tanto em sociedades pré como industriais. No trabalho de Daniel Miller (2002), por exemplo, vemos que o que orienta a escolha dos objetos a serem adquiridos é o amor. Ainda que sua argumentação esteja fundada na observação de uma dimensão prosaica como o abastecimento cotidiano do lar, sua análise oferece subsídios para pensarmos o consumo como um ato fundado em uma cosmologia que liga gerações. A devoção identificada através da ideia de amor é menos aos objetos que um processo dialético de constituição de uma ligação entre comprador e consumidor, através dos artefatos.

No caso aqui analisado, os artefatos são peças importantes tanto na dimensão da produ- ção, como na do consumo, e também nas esferas profissional e familiar. A exposição de 1969 foi um marco importante na trajetória de Olly, com impacto em seu reconhecimento e na expansão de sua clientela/rede de relações. Segundo depoimento do filho da artista, após essa exposição, "todo mundo queria uma roupa com pintura karajá. A casa vivia cheia"10. A compra de arte consistia, principalmente nas décadas de 1950 a 1980, em redes de mediação menos extensas que hoje: o consumo era parte de um processo quase sempre direto de interação entre o comprador e o produtor.

Para pensar o processo de produção e consumo na trajetória dessa artista é preciso levar em conta o contexto onde aconteciam essas "etapas11", tanto quanto os espaços de apresentação dessa produção. Museus e galerias de arte eram os locais onde as roupas eram apresentadas para serem admiradas, como fetiches de uma dimensão da arte moderna brasileira. Ali construía-se o valor de unicidade e a vinculação dessas roupas com o universo artístico. Não se falava em desfiles, mas em happenings, que eram apresentados pelas colunas de arte do Correio da Manhã, empresa de propriedade do marido da diretora do MAM. O que hoje seria chamado de apresentação de uma coleção de moda era classificado como exposição12. Ali sua produção era convertida em arte. No entanto, quando se levava em conta a função prática de vestimenta, ou seja, ao serem adquiridas para uso por seus clientes, a dimensão aurática da "obra de arte" era novamente reconvertida em roupa. Na tentativa de construir uma ponte entre a funcionalidade e a estética, Olly argumentava que seus vestidos serviam para "usar e pendurar na parede".

Mas não era só pelo discurso que passava essa construção. Tanto a produção, como o consumo desses objetos se davam no apartamento de Olly13. Ali, ela apresentava não somente sua produção, mas a si mesma através da exibição de uma profusão de objetos por ela adquiridos, que contribuíam para valorizar seu trabalho oferecendo a este um contexto. As viagens ao Peru e seu contato com antropólogos, arqueólogos e museólogos legitimavam a qualidade e autenticidade das peças expostas em seu apartamento14. Para analisar a trajetória de Olly é importante então tanto pensar o que ela produziu e foi consumido por outros, como o que ela consumiu para transformar no contexto de sua produção. Consumo e produção são aqui parte de uma dialética da qual é inócuo buscar uma relação causal ou uma origem.

Entretanto, também devemos considerar tanto as coisas que participaram do processo de circulação -o que foi vendido, dado ou trocado- como do que foi mantido à margem da esfera econômica. Estou considerando aqui, principalmente, a coleção de peças pré- -colombianas, os objetos indígenas e da cultura popular acumulados pela artista. Não se trata de posses inalienáveis, no sentido conferido ao termo por Annette Weiner (1992), mas 
da construção de valores transcendentes e da objetificação de suas relações sociais através de uma ideia de sensibilidade compartilhada.

É importante notar que se hoje as grandes feiras de arte permitem o acesso das classes médias à produção artística, até o final do século XX, esse consumo era restrito aos grupos economicamente privilegiados e aos intelectuais, principalmente aqueles vinculados à produção cultural. A habilidade de Olly, ou seja, sua capacidade de percepção e ação, na escolha dos objetos acumulados assim como no aproveitamento de temas na sua produção -seja a abstração15 ou os assuntos, ao mesmo tempo, partícipes de uma pretensa formação "nacional" e de debates pós-colonais- era parte de um engajamento ativo com as diversas dimensões constituintes de seu ambiente (Ingold, 2002).

O marido de Olly era um intelectual orgânico, membro do Partido Comunista no Brasil e refugiado da Alemanha tanto por sua origem judaica, como por sua participação em organizações partidárias de esquerda. Dentre o material bibliográfico do casal, encontram-se livros e artigos de jornal que remetem ao processo e às criticas pós-coloniais. Um casamento que durou quase cinquenta anos, numa aliança tão próxima que vemos fotos de Werner em sessões de fotografias dos trabalhos de Olly, precisamos considerar a influência que seus interesses e sua rede de relações teve nas escolhas da artista16. Ao mesmo tempo, a relação de Olly com Berta e Darcy Ribeiro, Noel Nutels, Augusto Rodrigues, Roberto Pontual, Jean Boghicci, entre outros, proporcionava um ambiente no qual indígenas, cultura popular, pré-colombianos eram temas política e artisticamente valorizados, também por sua dimensão crítica ao colonialismo, interno e externo.

A dialética entre produção e consumo, vista a partir do trabalho de Olly, era a criação de um mundo marcado pela mistura de materiais, estilos e formas de constituição de si: rusticidade e modernidade eram expressas pelas coisas produzidas e consumidas por ela, seus clientes e outros participantes de sua rede de relações e, ao mesmo tempo, constituí- am essas pessoas como um grupo delimitado a partir de formas específicas de percepção do mundo e produção de si. Olly consumia para se produzir como produtora artística e, portanto, seus produtos eram marcados pelo que ela consumia. Essa dialética não é uma particularidade apenas de sua trajetória.

Na década de 1960, em suas viagens ao Peru, entrou em contato com as escavações arqueológicas e os objetos cerâmicos pré-colombianos. Acumulou uma razoável quantidade dessas peças e também de tecidos Paracas17 e bonecas de tecido18. Tratava-se de um consumo suntuário que compunha o ambiente no qual sua subjetividade era construída a partir de objetos que contariam histórias e constituiriam o reconhecimento de seu nome. Essas coisas eram parte importante do sistema de trocas, ainda que ela os mantivesse fora de circulação, enquanto ofertava sua produção. Como as conchas e os homens do kula, ambos "são reciprocamente agentes na definição de valor um do outro" (Appadurai, 1983). O valor das coisas acumuladas por Olly estava em seu potencial colecionável. Esses artefatos foram importantes para a valorização de sua produção, mas também para a transformação do contexto social e político do período em tela, contribuindo com a construção da ideia de diversidade que constituía parte importante dessa hermenêutica de modernidade que se instituía. Para se compreender essa participação política de suas coisas em uma ideologia fundada na ideia de diversidade nacional é necessário investigar seus tecidos não apenas a partir da dimensão de troca, mas de sua produção e uso como repositórios políticos e de riqueza.

Patrimônio e domicílio: produção de si e construção de transcendência 
Os artefatos por ela acumulados ficavam expostos em seu apartamento, compondo um ambiente que misturava plantas tropicais, arte moderna, em sua maior parte brasileira e latino-americana e moveis desenhados por arquitetos brasileiros e europeus que imigraram para o Brasil. Essas coisas comporiam mais tarde a coleção de coleções que vem sendo investigada19. Eclético, esse conjunto contava com objetos em materiais diversos barro, ferro, tecido, madeira, pedras, quadros, desenhos, entre outros- e de origens diversas -indígena, précolombiana e objetos coletados em áreas do Brasil rural, principalmente20.

A ideia de coleção é usada aqui para se referir ao conjunto, hoje fechado, de coisas acumuladas por Olly, que não se perderam após sua morte21. A lembrança do apartamento e dos objetos apareceu em todas entrevistas com pessoas que passaram pela casa do casal. A referência às "coisas" de Olly sempre veio acompanhada de elogios ao "gosto" da artista e à qualidade de suas escolhas. Essas "coisas", entretanto, não estavam restritas à coleção pré-colombiana ou aos objetos considerados colecionáveis e/ou musealizáveis, mas se referiam também a artefatos diversos como joias, cinzeiros, plantas, talheres, pratos, copos, travessas para servir comidas e outras peças de decoração e uso cotidiano. Portanto, os objetos pré-colombianos, indígenas ou da cultura popular eram parte de um universo, cujo eixo central era Olly, e do qual faziam parte diversas outras coisas por ela adquiridas. Ao questionar os entrevistados especificamente sobre o possível sentido da aquisição das cerâmicas pré-colombianas e objetos indígenas, o termo patrimônio surgiu como justificativa. Patrimônio sugere ao mesmo tempo a continuidade do sujeito, através da capacidade narrativa de gerar objetos significativos e engendrar um outro significante, e a inserção do sujeito em um contexto maior de pertencimento, o Estado e a História. Diz respeito, ao mesmo tempo, à genealogia do sujeito, vinculando gerações através dos objetos, à construção de redes de relação pela comunhão através do tipo de patrimônio acumulado e à cosmologia de pertencimento nacional conectando a artista ao Brasil e América Latina, através de seus mitos de origem22. Portanto, patrimônio refere-se ao futuro, ao presente e ao passado.

Assim, são reconhecíveis algumas das características definidoras da ideia de coleção: além dos objetos ficarem expostos aos olhos de seus visitantes, a partir de um sistema de classificação que os separava em totalidades aparentemente identificáveis -indígenas, pré-colombianos e cultura popular-e terem sido separados do circuito de atividades econômicas (Pomian, 1984), eles também constituíam parte de um jogo artístico (Stewart, 1993) particular à forma de participação no campo artístico naquele contexto histórico. Fazia parte desse jogo retirá-los física e simbolicamente de seus contextos históricos e culturais, apagando o processo de produção que deu origem aos objetos e suas funções prá- ticas, para usá-los como peças no tabuleiro da modernidade artística brasileira a partir de uma dimensão ainda não nacionalizada, a moda pensada como design. O contexto desses objetos passava a ser o de sua acumuladora/colecionadora, falando não mais da história e cultura dos povos que os produziram, mas da trajetória da artista inserida no processo de produzir um design de moda autenticamente nacional. Talvez por isso não haja, entre os documentos do Acervo Olly e Werner Reinheimer23, nenhuma referência aos povos que produziram os objetos ou aos locais de aquisição dos mesmos.

Essa supressão é o que permite que os objetos apareçam na fala dos entrevistados como diretamente relacionados à subjetividade de Olly e seu trabalho e não às sociedades que os produziram ou o contexto de sua aquisição. As coisas foram citadas em situações diversas. Algumas vezes apareciam em alguma história na qual se destacava certo jogo performático que incluía o preparo de alimentos, as louças e a forma como eram servidos aos convidados. Essas histórias eram sempre contadas como se a performance e a estética fossem resultado de uma improvisação, por sua vez, consequência da habilidade da artista no cuidado doméstico e como anfitriã. 
Esse cuidado foi também mencionado por Olly em seus manuscritos, onde justificou fazer o serviço doméstico para economizar, no intuito de comprar coisas. O termo utilizado para se referir a esse trabalho foi o "cuidado com a casa", o que carrega consigo certo desafio às marcações de classe no Brasil sendo, ao mesmo tempo, uma afirmação de sua germanidade e a concomitância da produção profissional e a produção de si enquanto esposa e mãe. O cuidado da casa aparece então como cuidado de si e de sua rede de relações. Sua produção de tecidos e roupas, ainda que forma de ingresso em uma dimensão profissional, também não pode ser pensada como apartada da dimensão doméstica e familiar. Pelo contrário, a dimensão doméstica era constitutiva da produção de si no campo artístico.

Algumas das reportagens sobre suas exposições, ao longo da década de 1960, afirmam a concomitância dessas dimensões de trabalho. Ainda que por parte da mídia essas afirma- ções possam ser compreendidas como uma estratégia do feminismo da época em defender a possibilidade de ingresso da mulher no mercado de trabalho, sem abandono da vida familiar e doméstica, é significativo terem sido mencionadas também pelos entrevistados. Ressaltou-se o apartamento de Olly como uma "casa aberta" aos amigos que apareciam de surpresa e eram recebidos com refeições improvisadas, marcadas pela estética, devido aos objetos usados e também à performance teatral da anfitriã. Ter a "casa aberta" para os amigos e conhecidos era uma forma de interação frequente entre o grupo do qual Olly e seu marido participavam no período em tela24. O investimento da artista na improvisação e no cuidado com os objetos na apresentação das comidas e bebidas foram ressaltados nas menções a esses encontros, mas sempre acompanhados de um comentário sobre sua habilidade na cozinha, com ênfase no fato de que era ela mesma quem cozinhava para os convidados.

No Brasil, delegar o serviço doméstico é parte de uma prática hierarquizante, onde as classes médias liberam seu tempo para o trabalho ou lazer contratando para os serviços cotidianos da casa pessoas de grupos econômicos significativamente menos privilegiados. Esse tipo de trabalho tem um significado social de marcação de diferenças em termos sociais e culturais. Na análise de Giralda Seyferth sobre as tentativas do Estado Novo, entre 1937 e 1945, de transformar os usos e costumes dos imigrantes alemães, no sul do Brasil, uma das diferenças marcantes para os autores das biografias utilizadas eram as diferenças de comportamento de gênero em relação aos padrões brasileiros.

Os comentários sobre o "reduzido número de servos" e o fato de que mesmo as mulheres de famílias ricas faziam serviços domésticos (Seyferth, 1997, p. 117) é parte do mesmo sistema de valores que Olly acionava relacionado a uma marcação étnica que passava pela ética do trabalho. Sua germanidade era mencionada em quase todos os artigos de jornais, revistas e livros sobre a artista, mas a referência mais explícita ao sentido dessa menção está em um artigo que não falava sobre ela. Trata-se de uma coluna de um autor que poderia ser alemão, Guenter Bandman, na revista semanal DN, de Salvador. A coluna falava da semelhança em pintores alemães dispersos por outros países e sua relação com o expressionismo (Der Blaue Reiter, Die Brucke etc) e nomes como Kokoschka, Emil Nolde, Pechstein, entre outros.

Nesse período, Olly expunha no Museu de Arte Moderna da Bahia, em Salvador. Uma semana antes, no mesmo periódico, um artigo de duas páginas, com várias fotos, falava de sua fuga do nazismo, em 1936, e de seus tecidos "internacionalmente" famosos. Lar e trabalho apareciam lado a lado para compor a identidade da artista: "sabe perfeitamente dividir as horas do dia, para se dedicar à sua arte e ao seu lar. Pela manhã integra-se nas atividades do "atelier". À tarde e à noite vive a vida doméstica de toda mãe, de toda dona de casa" (DN, 1961). Na semana seguinte, a coluna sobre os artistas alemães não mencionava Olly. No entanto, uma foto de dois 
tecidos seus aparecia na parte superior da coluna, como se a estivesse ilustrando. Acima dos tecidos lia-se, “Tecidos de Olly no MAMB" (Revista DN, 1961b). Tão significativo como a diagramação, é o fato de que, ao contrário da maioria das colunas sobre seu trabalho e exposições, Olly guardou não somente o que se referia a ela -ou seja, a foto-, mas a página toda, com a coluna sobre os alemães.

Provavelmente influenciada por uma ilusão biográfica, a irmã de Olly falou em diversas ocasiões do interesse da artista, desde sua juventude, em uma formação profissional no domínio da criação artística. No entanto, somente na década de 1950 ela começou essa formação encontrando no tecido o suporte para a pintura, o bordado e a bricolagem. Vânia Carneiro de Carvalho (2008) encontra nos tecidos que cobrem os móveis da casa a marcação de espaços femininos nos lares burgueses do início do século XIX, no Brasil. No caso de Olly, tecidos e fios foram tomando conta de sua vida, confundindo o privado com o público e marcando em seu apartamento o espaço de sua atuação profissional, definindo também sua rede de relações e sociabilidade.

Grandes peças de algodão eram pintadas em uma mesa ampla que tomava quase todo o quarto, que um dia havia sido de seu filho. Em um segundo quarto, a função de dormitó- rio era secundária ao papel de provatório para seus clientes. Na cozinha e área de serviço, as tintas eram feitas, fios e tecidos tingidos e os tecidos pintados colocados para secar. Na sala, mas também no terceiro quarto -onde Werner dormia e recebia seus convidados- exibiam-se os diversos objetos que compunham o universo particular de Olly.

Sua opção pelo algodão, no momento de entrada do fio sintético no mercado brasileiro de vestimentas, era coerente com seu discurso sobre o artesanato de seu fazer, constituindo uma continuidade com a apropriação das expressões de grupos pré-industriais. Grande parte de seu processo artístico era produzido por ela: o tingimento de seus fios, a produção de suas tintas, a pintura dos tecidos usados em suas roupas e a própria costura e acabamentos. Essa dimensão de seu trabalho foi ressaltada no depoimento do crítico de arte Frederico Morais25. O último de seus investimentos, antes de sua morte, foi a produção de papel artesanal fundada, dessa vez, no discurso da preservação ambiental. Para produzir seus papéis, usava o fogo para desfazer as fibras de diferentes tipos de materiais: legumes, fibras, tecidos. Em uma carta a uma amiga, a artista comenta zombeteira sobre seu artesanato: "Werner fica na porta [da cozinha] perguntando se é comida ou papel. Quase sempre é papel mesmo" (CO-101, s/d).

Apostar no tecido "natural" era então seguir a lógica de uma interpretação de modernidade que aliava a racionalidade do design ao discurso de origem pré-colonial, pré-industrial, pré-capitalista. Entre suas contradições estava, além da dimensão política de uma esfera pretensamente apolítica -a arte- a aposta na origem pré-capitalista como tema de uma modernidade fundada nas marcas de um trabalho manual que se tornavam honoríficas e uma forma de discriminação em relação aos bens produzidos por máquinas. A rusticidade, forma de enaltecimento do multiculturalismo e da diversidade, justaposta às qualidades de singularidade e unicidade do objeto individual tornava-se uma forma de distinção em relação à serialidade da produção industrial (Veblen, 1953, p. 114), distanciando, também pelo valor de troca, os grupos que formavam o eixo de seu trabalho.

Considerações finais: Tecendo um mundo de diferenças

A partir da década de 1970, quando a tecelagem passou a ser seu principal meio de produção artística, um tear de um metro por um metro e meio passou a ocupar a área de serviço do apartamento de Olly, uma roca antiga 
"enfeitava" o ateliê e fios coloridos estavam sempre sendo organizados para serem transformados em urdimento de suas produções. Os fios que passaram a ocupar a quase totalidade do apartamento eram de cores intensas: roxo, amarelo, vermelho, magenta, turquesa. As cores e também a temática foram em grande medida influenciadas por seu contato com os tecidos Paracas26. De acordo com uma informante, pareceu uma transição fácil, do tecido ao tear, passar dos fios de seus bordados, que começaram a pender das roupas e ganhar espaço (Ver Figura 2), até se tornarem eles mesmos a matéria prima para a tecelagem.

Ingold utiliza o verbo tecer para elaborar uma ecologia da vida que supõe que as habilidades não são nem inatas, nem adquiridas, mas cultivadas, incorporadas no organismo humano através de prática e treinamento no ambiente. $O$ autor propõe inverter a idéia de que ao invés da tecelagem ser uma forma de fazer, o fazer seja uma forma de tecelagem, colocando a ênfase no caráter hábil do processo de geração de forma, ao invés de no produto final. Essa mudança de ênfase abre uma nova perspectiva para todo o tipo de habilidades práticas de geração de formas.

Para ele, a oposição entre fazer artefatos e cultivar organismos coloca em cena pressuposições complicadas acerca de oposições como natureza e mente, interioridade e exterioridade e a gênese da forma. Enquanto o design de um organismo é atribuído aos genes que são hereditariamente transmitidos, aos artefatos considerase que a relação entre forma e substância é invertida, sendo uma imposição da mente humana aos materiais inertes.

No processo de tecelagem, a superfície não é transformada, mas construída. A forma da cesta [objeto tecido que ele usa como exemplo], não emana da ideia, mas "surge do desdobramento gradual desse campo de forças criado através do envolvimento ativo e sensual do praticante e do material. Este campo não é interno ao material nem interno ao praticante (portanto, externo ao material); em vez disso, atravessa a interface emergente entre eles". A forma emerge então através de um padrão de movimento e da repetição rítmica desse movimento que dá origem à forma (Ingold, 2002, p. 342).

O artefato então é gerado a partir do que Ingold chama de um campo de forças. Os moldes, as medidas e as regras de ouro do artesão acrescentam aos artefatos um projeto que define os parâmetros do processo, mas não predefinem a forma. Enfatizar o fazer é considerar o objeto como a expressão de uma idéia, ao passo que enfatizar a tecelagem é considerá-la como a incorporação de um movimento rítmico. Esse movimento não é somente o movimento das mãos e do corpo do artesão, que vão dando forma ao artefato, mas também o movimento de inserção em determinado campo de forças, redes/malhas de relações sociais, coisas e suas tecelagens, ritmos, variações, cores, texturas.

A tecelagem, última técnica usada por Olly na produção de suas roupas, pode então ser tomada tanto como uma metáfora, como uma conexão substantiva com o ato de Olly tecer sua trajetória a partir da apropriação das questões, objetos e contextos que atravessaram os ambientes (surroundings - Ingold, 2002) dos quais participou. O contato com a história dos povos pré-colombianos em suas viagens ao Peru pode ter significado uma forma de abrir caminho para o ambiente sensorial que Olly desenvolveu posteriormente. Segundo uma das entrevistadas, sua gama cromática, assim como o surgimento de motivos figurativos influenciados pelas tecelagens Paracas, pode ser notado a partir dessas viagens. 
A participação nos ateliês de arte do Museu de Arte Moderna do Rio de Janeiro já tinha oferecido uma linguagem através de materiais e técnicas artísticas que permitiram uma nova forma de relação com seu entorno. A aquisição de habilidades artísticas -cores, perspectiva, a história da arte moderna, técnicas variadas como gravura, cerâmica, pintura- mudou sua forma de engajamento com o ambiente. Como se sua atenção tivesse sido educada para perceber a produção pré-colombiana a partir de valores caros aqueles intelectuais que inventavam uma modernidade brasileira. Suas coleções de cerâmica pré-colombiana, coisas indígenas, literatura de cordel, entre outras, foram uma forma de incorporar essas experiências em suas criações, mas foram elas mesmas uma maneira de objetificar os valores de sua rede de relações.

Olly iniciou sua trajetória profissional trabalhando com tecidos e roupas a partir de uma formação artística, dentro do Museu de Arte Moderna do Rio de Janeiro. Esse museu propunha, naquele contexto, a constituição de uma modernidade nacional que, para um amplo conjunto de agentes, passava pela união da racionalidade com uma sensibilidade associada ao pré-industrial, pré-moderno. A ideologia da miscigenação, recentemente resgatada de sua dimensão negativa por Gilberto Freire, constituiu o eixo em torno do qual se estruturava a positividade de uma autenticidade nacional e foi incorporada em algumas situações como forma de apresentar novas tecnologias com roupagem nacional.

Sem minimizar a qualidade de seu trabalho, contribuiu para a aceitação de Olly no incipiente campo artístico do período a possibilidade de incluir nessa modernidade nacionalista a dimensão da moda, fenômeno que na década de 1950 ainda era majoritariamente baseada na produção europeia. O design, como forma de incluir a dimensão estética na indústria, era reivindicado também para esse fenômeno27 e a existência no MAM de um grupo de designers facilitava a produção de discursos que inserissem os tecidos e roupas de Olly no campo da produção artística.

O algodão e a lã, materiais privilegiados por Olly, assim como o artesanato de sua produ- ção eram condizentes com essa aliança entre modernidade/racionalidade e rusticidade/ sensibilidade. No entanto, antes de assumir a produção dos grupos pré-industriais como base para sua produção, Olly pintou tecidos coloridos sem formas realistas. Essa opção aproximou-a de críticos como Mário Pedrosa, que defendiam naquele período a abstração como modernidade artística.

Diversos intelectuais que faziam parte de sua rede de relações devido à participação no campo artístico e/ou por seus vínculos com as imigrações do entre-guerras compartilhavam sua apreciação estética da cultura material indígena, popular e pré-colombiana, se afinando com a proposta de instrumentalização dessas manifestações, por parte da UNESCO. A formação de diversas coleções relacionadas a esses grupos minoritários objetificava sua sensibilidade, estreitando seus laços a partir de valores caros a esses antropólogos, arqueólogos, museólogos, artistas e colecionadores que também reconheciam na estética uma habilidade desses grupos, ao mesmo tempo que uma ferramenta política para desconstruir os estigmas de que eram alvo.

Na década de 1960, acrescentou-se ao conjunto de fatores que tornavam o contexto social e institucional da década anterior propícios ao seu reconhecimento como artista, seu crescimento e amadurecimento pessoal e profissional. Esse desenvolvimento foi concomitante à volta de um debate feminista que pautava a importância da profissionalização da mulher como forma privilegiada de luta pela igualdade de direitos. Profissionais como Betty Friedan, Elizabeth Bishop e Irene Kassorla, cada uma em sua área e de diferentes formas, representaram esses debates. Olly, à sua maneira, também simbolizava a luta pela emancipação feminina do período. Talvez 
por isso, as três adquiriram roupas feitas por Olly e Clarice Lispector, insatisfeita com ter somente uma roupa, usou-a em um conto como analogia para a felicidade e a vida28.

Ser feminista não significava abraçar a carreira e colocar a família em segundo plano, mas mostrar que era possível fazer as duas coisas e ainda manter a casa aberta para receber os amigos, como faziam diversos intelectuais/homens da época. A inquietude e energia de Olly permitiam que ela cumprisse essa dupla jornada. Sua percepção da importância dessa dimensão como parte constitutiva de sua subjetividade parece incontestável no uso explicito que fazia disso em seu discurso em diversas colunas que falavam sobre seu trabalho e/ou exposições.

No entanto, ter uma profissão e ainda trabalhar em casa não eram dimensões facilmente defensáveis em uma sociedade cuja elite para quem seus produtos eram dirigidos procurava se distinguir pela quantidade de empregados domésticos e uma afirmação de status contrária à ética do trabalho. Marcar uma postura feminista pelo trabalho, nesse contexto, não podia então prescindir do reforço à sua origem alemã, ainda que quando contestada diretamente sobre sua nacionalidade, sua opção fosse pela identidade brasileira. Nesse sentido, sua trajetória ilustra a instabilidade da identidade, constantemente redefinida em função da situação, e a necessidade de se considerar sempre as questões de gênero atreladas à etnicidade.

Seu apartamento aparecia aí como um objeto, repleto de objetos, ou uma galeria/museu/showroom para suas diversas coleções, dentre elas, a de roupas. Na década de 1960, quando a ideia de uma moda brasileira ainda não era completamente aceita, uma das estratégias para construir essa como uma dimensão legítima foi aproxima-la da arte. Assim, ainda que as colunas que falavam de seu trabalho e suas exposições mencionassem a singularidade de sua produção de moda, Olly se considerava e era considerada por muitos como uma artista.

Em conversa com uma importante galerista, perguntei se ela tinha alguma coisa de Olly. A pergunta poderia ser interpretada, como foi por outras pessoas, como referida a roupas. No entanto, sem hesitar ela explicou que naquela época (década de 1970), as galerias não costumavam constituir coleções com as obras dos artistas expostos, claramente classificando o trabalho de Olly como arte. Nessa década, no entanto, quando a idéia de uma moda brasileira já não parecia tão estranha, em algumas matérias de revistas, Olly se auto- -denominava estilista.

Os tecidos produzidos por Olly estimulavam o consumo a partir de justificativas diversas: a idéia de democracia racial que sustentava uma "autenticidade nacional" era provavelmente a razão para que diplomatas e suas esposas adquirissem e/ou financiassem suas exposições no Brasil e em outros países; a profissionalização feminina como eixo central de certos discursos feministas provavelmente foi o que levou Betty Friedan, Elisabeth Bishop e Irene Kassorla a seu ateliê; uma crítica pós-colonial das relações de poder entre o Estado e os grupos minoritários pode ter sido o sentido para alguns intelectuais de sua rede de relações e uma hermenêutica de modernidade vista como a união da tecnologia e racionalidade com materiais e temas de grupos pré-industriais provavelmente atravessava todas as justificativas.

Independente de como cada um justificava o "gosto" por suas coisas, seu trabalho foi parte do processo de formação de um campo artístico relativamente autônomo no Brasil e sua expansão com a incorporação da diversidade rumo a uma linguagem contemporânea, a partir dos anos 1950, baseada na crescente percepção da 
multiplicidade gerada pela descoloniza- ção. Foi parte constitutiva dessa ampliação a transformação de objetos etnográficos em arte. Uma trajetória análoga ao campo artístico poderia ser percebida na formação da ideia de "moda brasileira". O modernismo das décadas de 1910 a 1940 buscou na alteridade interna o distanciamento do classicismo europeu e a construção de uma linguagem moderna. Essa modernidade abriu caminho para o rompimento com o assunto e a instituição de uma forma de expressão, a abstração, que tornava as técnicas, os materiais pictóricos e outras questões internas à obra de arte critérios propícios para uma crescente autonomização das avaliações estéticas.

O trabalho de Olly pode ser vinculado a estilistas que desde a década de 1940 estavam buscando em temas relacionados à diversidade brasileira uma maneira de construir a paricularidade nacional (Bonadio, $2014 \mathrm{e}$ Bonadio e Araújo, 2010). A institucionalização de uma moda brasileira, entretanto, parece ter se dado algumas décadas mais tarde com o rompimento da temática e uma ênfase em técnicas tradicionais, materiais nacionais e a utilização destes a partir de designs contemporâneos. No entanto, guardadas as propor- ções, analogamente ao campo artístico, a diversidade étnica, cultural e regional retornou como mais um dos múltiplos modos de produção de uma moda contemporânea. Daí que uma das formas mais polêmicas de interpretação do Plano Nacional de Cultura, de 2012, que inseria a moda como uma das dimensões culturais nacionais, ter sido a apropriação da produção de vestuário de diversos grupos minoritários por parte de alguns estilistas. Chamar o que Olly fazia de arte era assim uma forma historicamente determinada de objetificação da sua produção de roupas.

Notas

1. Esse artigo é parte de um projeto de pesquisa que obteve verbas do CNPq e da Faperj.

2. Nesse ano, inaugurou-se o Museu Quai Branly, em Paris, primeiro museu com discurso explícito de estetização/artificação dos objetos da cultura material de povos pré-industrializados (Price, 2007).

3. As duas mais importantes para os debates antropológicos, pela repercussão que a elas deram autores consagrados do campo, foram "Primitivism in 20th Century Art: Affinity of the Tribal and the Modern", organizada pelo MoMA, em 1984, e "Magiciens de la Terre", apresentada no Centre George Pompidou e no Parque La Villette, em 1989.

4. Essa universalidade pode ser representada pela defesa da abstração que, no Brasil e em outros países, simboliza a institucionalização da "modernidade artística" e a inauguração do debate contemporâneo na arte (Reinheimer, 2013).

5. Além dela, podemos destacar em sua rede de relações, Jean Boghicci que participou de coletas de objetos em áreas rurais no Brasil, na década de 1940, Franco Terranova, primeiro galerista de arte moderna no Rio de Janeiro, que tinha uma coleção de ex-votos e carrancas e Roberto Pontual e Jacques Van de Beuque, que colecionavam arte popular, tendo esse último formado o museu Casa do Pontal, com sua coleção.

6. Fotógrafo que ficou famoso no Brasil pelas fotos de moda que produzia, em um momento em que não havia ainda essa especialização na fotografia. 
7. Nascido na Alemanha, em 1928, estudou em Ulm entre 1951 e 1953 e entre 1956 e 1958 trabalhou com Max Bill. Chegou ao Brasil em 1959, com uma bolsa do governo brasileiro, instalando-se em São Paulo. Em 1963, participou da instituição da ESDI (Escola Superior de Desenho Industrial), hoje parte da UERJ (Universidade do Estado do Rio de Janeiro). Em 1967, mudou-se para o Rio de Janeiro e começou a trabalhar no MAM, onde estruturou o Instituto de Desenho Industrial (IDI-MAM), em 1968, que mais tarde se uniria à ESDI.

8. Não há confirmação de que, de fato, tenha seguido para esses países.

9. Essas denúncias resultaram na extinção do Serviço de Proteção aos Índios (SPI) e cria- ção da FUNAI.

10. Concedido à autora em 1998.

11. O uso do termo etapa aqui é meramente heurístico, haja vista que não há uma separação clara do que é produção e do que é consumo, pois consumir era também uma forma de produção de si e de coletividades, tratava-se de um processo em que as ações se influenciavam e constituíam mutuamente.

12. O MAM tem sido, nos últimos anos, palco de um grande evento anual de moda. Nesses eventos não se fala em exposições ou happenings, mas em desfiles e shows de moda. Se a partir da década de 1990, no Brasil, o ensino de moda foi incluído na esfera do design -debate que teve início na década de 1950, com o MAM-, hoje a apresentação do trabalho de estilistas e designers de moda se aproxima mais do show business.

13. Por um curto período de tempo, entre 1972 e 1974, Olly teve um ateliê em um apartamento próximo ao seu, mas antes e depois desse período seu apartamento foi o espaço onde produzia suas roupas e recebia seus clientes.

14. Em declaração a um periódico sobre as roupas que apresentou na Pinacoteca de São Paulo, cuja influência era dos grupos pré-colombianos, Olly argumentou que a ideia de usar essa produção como base para a sua foi do diretor do museu de arqueologia de Lima.

15. Quando Olly começou a pintar tecidos na década de 1950, abstração e figuração eram parte de uma disputa pela legitimidade da classificação de objetos artísticos. No início da década de 1960, quando o maior defensor do abstracionismo no Brasil, Mário Pedrosa, assumiu a diretoria do Museu de Arte de São Paulo e da Bienal de São Paulo, essa disputa foi encerrada com a institucionalização da arte moderna como a manifestação artística mais reconhecida (Reinheimer, 2013). Iniciou-se então nova disputa com o que viria a ser posteriormente classificado como arte contemporânea. As duas primeiras exposições de Olly, em 1958 na Galeria Contemporânea e em 1960, no MAM, contavam com tecidos pintados com manchas abstratas e pendurados na parede como se fossem quadros, sem moldura.

16. O mesmo tipo de atravessamentos temáticos entre maridos intelectuais e esposas artistas pode ser percebido em entrevistas com diversos outros casais que faziam parte da rede de relações da artista.

17. A cultura Paracas (400-100 a.C.) surgiu na costa sul do Peru e é conhecida por sua produção têxtil elaborada, usada nos ritos funerários. Essa cultura deu origem à Civiliza- ção de Nazca.

18. São mais de cem peças em cerâmica, tecido e telas. 
19. Esse projeto tem o patrocínio do CNPq e da FAPERJ e consiste em sistematizar, digitalizar e disponibilizar online o Acervo Olly e Werner Reinheimer, ao mesmo tempo, investigando a trajetória do casal. Uma vez concluído o processo, o material estará disponível no endereço eletrônico http://r1.ufrrj.br/olly/index.php/

20. Menos de uma dezena desses objetos era proveniente de países asiáticos e africanos.

21. Muitas coisas foram vendidas, distribuídas entre o filho e os netos, ou perdidas.

22. Uma anedota relatada por um artista, amigo de Olly, coloca-a defendendo sua nacionalidade brasileira como mais legítima do que de seu interlocutor, que indagava sobre seu país de nascimento. Segundo Sérgio Campos Melo, ao invés de informar seu país de origem, irritada, Olly teria afirmado ser mais brasileira que ele, por ser esta uma opção e não uma aquisição por acaso de nascimento.

23. O Acervo Olly e Werner Reinheimer é o conjunto de documentos em papel, têxteis e objetos em materiais diversos que vem sendo sistematizado pelo projeto que engloba essa pesquisa.

24. Ruy Castro (1999) apresenta a formação do bairro de Ipanema a partir da década de 1910, prolongando as biografias de alguns personagens até o final da década de 1980. Nesse trabalho mostra a construção dos valores de uma contracultura que começou a se constituir principalmente na década de 1950, teve seu apogeu na década de 1960 e resistiu até o começo da abertura, no final da década de 1970. Nesse período, os grupos de interesses comuns em política, arte e cultura contavam com espaços de encontro tanto nos bares, na praia e nas praças, como em casas de intelectuais como Aníbal Machado, Lúcio Cardoso, Nelson Dantas, Rodrigo Melo Franco de Andrade e Mário Pedrosa, todos moradores do bairro. Pedrosa que ficara exilado do Brasil entre 1937 e 1945, quando foi morar em Ipanema, ajudou a fundar o Partido Socialista Brasileiro e recebia em sua casa, na Visconde de Pirajá, entre a Montenegro e a Farme de Amoedo, artistas e intelectuais para debates. Nelson Dantas, ator e diretor de TV, teatro e cinema, entre 1953 e 1962, manteve sua casa aberta, na praça Nossa Senhora da Paz, aos sábados à noite, para amigos e amigos de amigos. Em 1964, foi a vez de Plinio Doyle abrir sua casa. Aos sábados à tarde, desde o natal de 1964, vários amigos romancistas, historiadores, memorialistas, poetas, e outros apareciam para conversar.

\section{Depoimento concedido em 2014.}

26. Na década de 1960, junto com os objetos cerâmicos, Olly adquiriu uma coleção de tecidos paraca, no Peru. A coleção foi vendida após sua morte para um leiloeiro em Nova York.

27. Essa reivindicação só veio a se concretizar na década de 1990, quando a formação em moda foi incluída no currículo dos cursos superiores de design. Na década de 1960, formou-se no Rio de Janeiro a primeira escola superior de design, a ESDI (Escola Superior de Desenho Industrial - vinculada hoje à UERJ). Seu núcleo de professores no período era composto por alguns profissionais que também participavam do Instituto de Desenho Industrial do Museu de Arte Moderna do Rio de Janeiro.

28. O morto no mar da Urca, Clarice Lispector, 1974.

Referências bibliográficas 
Abreu, R. (2007). Tal antropologia, qual museu? In Museus, coleções e patrimônios: narrativas polifônicas I Regina Abreu, Mário de Souza Chagas, Myrian Sepúlveda dos Santos (orgs.) - Rio de Janeiro: Garamond, MinC/IPHAN/DEMU.

Belting, H. (2006). Arte universal e minorias. Uma nova geografia da história da arte. In O fim da história da arte: uma revisão dez anos depois. São Paulo, Cosac Naify.

Bonadio, M. C. (2014). A moda no MASP de Pietro Maria Bardi (1947-1987). Anais do Museu Paulista. São Paulo. N. Sér. v.22. n.2. p. 35-70. jul.- dez.

Bonadio, M. C. e Guimarães, M. E. A. (2010). Alceu Penna e a construção de um estilo brasileiro: modas e figurinos. In Horizontes Antropologicos, Porto Alegre, ano 16, n.33, p.145-175, jan./jun.

Bueno, M. L. (2005). O mercado de galerias e o comércio de arte moderna. Sociedade e Estado, Brasília, v. 20, n. 2, p. 377-402, maio/ago.

Campbell, S. (2010). A estética dos outros In Revista Proa, n02, vol.01.

Carvalho, V. C. de. (2008). Gênero e Artefato. O sistema doméstico na perspectiva da Cultura material- São Paulo, 1870-1920. Editora Edusp, São Paulo, .

Chagas, M. (2007). Museu do índio: uma instituição singular e um problema universal. In Manuel Ferreira Lima Filho, Cornelia Eckert, Jane Felipe Beltrão (Organizadores). Antropologia e patrimônio cultural: diálogos e desafios contemporâneos. Nova Letra, Blumenau.

Dias, C. \& Lima, A. C. de S. (2012). O Museu Nacional e a construção do Patrimônio In Revista do Patrimônio Histórico e Artístico Nacional. História e Patrimônio, n. 34.

Goldstein, I. S. (2012) AUTORIA, AUTENTICIDADE E APROPRIAÇÃO. Reflexões a partir da pintura aborígine australiana. RBCS Vol. 27 n 79, junho/2012.

Grupioni, L. D. B. (1998). Coleções e Expedições vigiadas: etnólogos no conselho de fiscalização das expedições artísticas cientificas no Brasil. SP: Hucitec/Anpocs.

Heinich, N. e Shapiro, R. (2012). When is artification? Contemporary Aesthetics, Special volume 4.

Ingold, T. (2002). The perception of the environment. Essays on livelihood, dwelling and skill. First published by Routledge, 2000. This edition published in the Taylor \& Francis e-Library,

Maio, M. C. (1998). "O Brasil no concerto das nações: a luta contra o racismo nos primórdios da Unesco". História, Ciências, Saúde - Manguinhos, Rio de Janeiro, Fiocruz, V (2): 375-413.

Mascelani, M. Â. (1999). "A Casa do Pontal e suas coleções de arte popular brasileira”. In: Revista do Património, n. 28, Rio de Janeiro/Brasllia: IPHAN (p 131-132)

Miller, D. (2002). Teoria das compras. O que orienta as escolhas dos consumidores. São Paulo: Nobel. 
Pomian, K. (1984). Coleção. Enciclopédia Einaudi, vol. 1 Memória-História. Imprensa Nacional Casa da Moeda, Lisboa.

Price, S. (2007). Paris Primitive. Jacques Chirac's Museum on the Quai Branly. USA: The University of Chicago Press.

Reinheimer, P. (2013). Candido Portinari e Mário Pedrosa: uma leitura antropológica do embate entre figuração e abstração no Brasil. Rio de Janeiro: Editora Garamond.

Seyferth, G. (1997). Assimilação dos imigrantes como questão nacional In Mana, volume 3, número 1, abril de 1997.

Smith, T. (2012). ¿Qué es el arte contemporáneo? Buenos Aires: Siglo XXI Editores.

Souza, G. M. (1987). O espírito das roupas. A moda no século dezenove. Companhia das Letras, 1987 [1950].

Veblen, T. (1953). A teoria das classes ociosas.

Weiner, A. B. (1992). Inalienable Possessions. The paradox of keeping-while-giving. Univesity of California Press, USA.

Weiner, A. B. (1985). Women of value, men of renown. University of Texas Press, Austin. Weiner, J. F. (introduction); Morphy, H. (for the notion 1); Overing, J. (against the notion 1); Coote, J. (for the notion 2); Gow, P. (against the notion 2). (1993) debate. Aestethics is a cross-cultural category. In Ingold, T. (ed.) Key debates in Anthropology. London, Routledge, 1996.

Fontes etnográficas

CO-101. Correspondência de Olly Reinheimer para Betty White e Stephen Strauss. Rio de Janeiro, sem data. Acervo Olly e Werner Reinheimer.

Revista DN. "Mãos que criam sonhos para vaidade da mulher", Salvador, 5 e 6 de fevereiro, 1961.

Revista DN. Salvador, 19 e 20 de fevereiro, 1961b.

Resumen: Esta comunicación analiza, a partir de la trayectoria y el trabajo de una artista textil teuto-brasileña, la participación de los objetos, colecciones y museos en la construcción de una realidad fenomenológica en la cual la alteridad fue tejida en ropas, color y textura. Los museos, pero principalmente los etnológicos, fueron el camino que llevó Olly hacia estos temas, así como los museos de arte moderno fueron una de las formas privilegiadas para el reconocimiento de su producción artística. Su contacto con antropólogos, coleccionistas y museólogos contribuyó a que asumiera esas temáticas en su producción, contribuyendo en la configuración de una modernidad imaginada para el país.

Palabras clave: moda - arte moderno - alteridad - diseño - nacionalidad - museos - colecciones. 
Abstract: This communication intends to present the trajectory and work of a TeutoBrazilian weaver. From there it will discuss objects, collections and museums' participation in the warp of a phenomenological reality where the otherness was woven in clothes as subject, color and texture. Museums, especially the ethnological ones, were Olly's path to her subjects, just as museums of modern art were one of the privileged ways to recognize her production as art. Her contact with anthropologists, collectors and museologists helped her to assume these themes in her production, contributing to the construction of an imagined modernity for the country

Key words: fashion - modern art - otherness - design - nationality - museums - collections.

[Las traducciones de los abstracts fueron supervisadas por el autor de cada artículo]

Tecendo um mundo de diferenças fue publicado de la página 191 a página212 en Cuadernos del Centro de Estudios de Diseño y Comunicación Nº76 